\title{
Role of interferon-gamma in inflammatory responses in murine respiratory infection with Legionella pneumophila
}

\author{
YOKO SHINOZAWA, TETSUYA MATSUMOTO*, KOU UCHIDA, SHIRO TSUJIMOTO†, \\ YOICHIRO IWAKURA: and KEIZO YAMAGUCHI*
}

Second Department of Internal Medicine, *Department of Microbiology and †Department of Hospital Pathology, Toho University School of Medicine, 5-21-16 Omori-Nishi, Ota-ku, Tokyo, 143-8540 and \$Laboratory Animal Research Center, Institute of Medical Science, University of Tokyo, Tokyo, Japan

\begin{abstract}
The role of interferon (IFN)- $\gamma$ in host inflammatory responses, including inflammatory cytokine production, in experimental pneumonia with Legionella pneumophila was examined in IFN- $\gamma$ knockout $\left(\right.$ IFN- $\gamma^{-/-}$) mice. IFN- $\gamma^{-/-}$mice and wild-type BALB/cA mice were inoculated intranasally with $L$. pneumophila strain $\mathrm{KC}$. The survival rate of IFN $-\gamma^{-/-}$mice was significantly lower than that of control mice. Viable bacterial counts in lungs and blood showed a rapid and continuous increase in IFN $-\gamma^{-/-}$mice, in contrast to a gradual decrease in the lungs and an intermittent bacteraemia in control mice. Histopathological analysis of $L$. pneumophila-infected lung tissues demonstrated mild pneumonia in control mice, whereas severe pneumonia was shown in IFN- $\gamma^{-/-}$ mice. During the late stages of infection, the number of total bronchoalveolar lavage (BAL) cells was significantly higher in IFN- $\gamma^{-/-}$than in control mice. The concentrations of tumour necrosis factor- $\alpha$ and interleukin-1 $\beta$ in sera of IFN- $\gamma^{-/-}$ mice were significantly lower in control mice during the early stages of infection, suggesting suppressed production of inflammatory cytokines in IFN- $\gamma^{-/-}$mice. In contrast, during the late stages of infection, the levels of these cytokines were significantly higher in sera of IFN- $\gamma^{-/-}$mice than in control mice, suggesting severe and systemic infection in IFN $-\gamma^{-/-}$mice. The findings suggest that retardation of host immune responses, including inflammatory cytokine production caused by deficiency of IFN- $\gamma$, might allow the bacteria to grow and cause fulminant pneumonia.
\end{abstract}

\section{Introduction}

Legionnaires' disease, an atypical form of pneumonia in man, is caused by Legionella pneumophila, a facultative intracellular pathogen that parasitises human alveolar macrophages and blood monocytes recruited into the lungs. Interferon-gamma (IFN- $\gamma$ ) is a potent activator of macrophages $[1,2]$ and is known to stimulate both human alveolar macrophages [3, 4] and monocytes [5] to resist L. pneumophila infection. Heath et al. [6] have already studied the role of IFN$\gamma$ in a model of experimental pneumonia induced by $L$. pneumophila in IFN- $\gamma$ knockout (IFN- $\gamma^{-/-}$) mice. They assessed the mechanism of impaired resistance

Received 26 March 2001: revised version received 20 Aug. 2001; accepted 4 Sept. 2001.

Corresponding author: Dr Y. Shinozawa (e-mail: shinozaw@med.toho-u.ac.jp). in IFN $-\gamma^{-/-}$mice by studying the role of endogenous reactive nitrogen intermediates, including nitric oxide (NO), and demonstrated that macrophage inducible nitric oxide synthetase (iNOS) was induced in alveolar cells from $L$. pneumophila-infected immunocompetent mice but not in similarly infected IFN- $\gamma^{-/-}$mice [6]. Furthermore, administration of iNOS inhibitor, Nmonomethyl-L-arginine, to immunocompetent mice caused significant inhibition of clearance of $L$. pneumophila from the lungs. Based on these findings, it was concluded that IFN- $\gamma$-mediated resolution of $L$. pneumophila pulmonary infection occurs by a NOdependent mechanism. However, the responses of other inflammatory cytokines in IFN- $\gamma^{-/-}$mice were not determined. It is possible that retardation of host immune responses may be caused not only by deficiency of IFN- $\gamma$ but also by low production of other inflammatory cytokines. To test this hypothesis, the kinetics of production of inflammatory cytokines in 
IFN- $\gamma^{-/-}$mice and wild-type control mice after pulmonary infection with L. pneumophila was investigated.

\section{Materials and methods}

Animals

IFN- $\gamma^{-/}$and wild-type BALB/cA female specific pathogen-free (SPF) mice were used. The wild-type $\mathrm{BALB} / \mathrm{cA}$ mice were purchased from CLEA JAPAN (Osaka, Japan). IFN- $\gamma^{-/-}$mice were generated by a targeted mutation of the IFN- $\gamma$ gene as described previously [7]. The genotypes of the IFN- $\gamma$ locus were checked by Southern blot hybridisation. Homozygous IFN- $\gamma$ gene knockout mice were produced by intercrossing heterozygous mice. IFN- $\gamma$ mRNA was detected by Northern blot hybridisation analysis and IFN- $\gamma$ protein was measured by an enzyme-linked immunosorbent assay (ELISA) [7]. All mice were housed in SPF conditions in the animal care facility at Toho University. The experimental protocol was approved by the institutional animal care and use committee of Toho University School of Medicine.

\section{Bacteria}

L. pneumophila serogroup 1 strain $\mathrm{KC}$, a clinical isolate from a patient with pneumonia caused by $L$. pneumophila, was used. The strain was kept frozen at $-80^{\circ} \mathrm{C}$ in brain heart infusion (BHI) broth containing glycerol $15 \% \mathrm{v} / \mathrm{v}$. For preparation of the bacterial inoculum, L. pneumophila was grown on buffered charcoal-yeast extract (BCYE) agar plates for $72 \mathrm{~h}$ and resuspended in sterile saline to a concentration of $1 \times 10^{9} \mathrm{cfu} / \mathrm{ml}$.

\section{Pulmonary infection with L. pneumophila}

IFN- $\gamma^{-/-}$and control mice were anaesthetised by subcutaneous injection of $0.1 \mathrm{ml}$ of a mixture of xylazine, ketamine $\mathrm{HCl}$ and saline, then inoculated intranasally with $40 \mu \mathrm{l}$ of bacterial suspension, which contained $4 \times 10^{7}$ cfu of L. pneumophila. Survival of infected mice was checked daily for 14 days after challenge.

At specific time points $(0,24,48,36,72$ and $96 \mathrm{~h})$ after intranasal inoculation of $L$. pneumophila, mice were killed. Cardiac blood and lung samples were obtained under aseptic conditions. The lungs were homogenised in $5 \mathrm{ml}$ of sterile saline with a tissue homogeniser. Portions of blood samples and lung homogenates were plated on to BCYE agar plates and incubated at $37^{\circ} \mathrm{C}$ for $72 \mathrm{~h}$. The numbers of $\mathrm{cfu} / \mathrm{ml}$ of lung homogenate and blood were subsequently determined. The remaining blood samples were allowed to clot at $4{ }^{\circ} \mathrm{C}$ in sterile glass tubes and then centrifuged at $10000 \mathrm{rpm}$ for $5 \mathrm{~min}$. Serum samples were preserved at $-80^{\circ} \mathrm{C}$ for measurement of cytokines.

\section{Broncho-alveolar lavage (BAL) and cell counting}

Following euthanasia by ether anaesthesia and exposure of the trachea, mice were intubated with a polyethylene catheter $(\mathrm{OD}, 1.0 \mathrm{~mm})$. The lungs were lavaged with $1 \mathrm{ml}$ of sterile saline via the endotracheal tube; $c$. $0.7-$ $0.8 \mathrm{ml}$ of lavage fluid were retrieved from each mouse. The cells in the BAL fluids were stained by Turk solution and the total cell count was determined with an optical microscope. BAL fluid was centrifuged at $10000 \mathrm{rpm}$ for $5 \mathrm{~min}$ and sediments were stained with Wright-Giemsa solution. At least 100 cells were counted under $\times 400$ magnification and identified as macrophages, lymphocytes and neutrophils according to the standard morphology.

\section{Cytokine assays}

Tumour necrosis factor-alpha (TNF- $\alpha$ ) and interleukin (IL)- $1 \beta$ levels in the serum were determined with commercial ELISA kits (BioSource International, CA, USA). The assays were performed exactly as described by the manufacturer and the level in each sample was determined in duplicate.

\section{Preparation of lung specimens for histopathological examination}

At specific time points after infection, other groups of mice were killed and the lungs were excised, inflated, fixed in buffered formalin $10 \%$, embedded in paraffin, sectioned at $10 \mu \mathrm{m}$ and stained with haematoxylin and eosin.

\section{Statistical analyses}

Differences in the survival rates between the two groups of mice were evaluated by the $\chi^{2}$ test. Viable bacterial counts and cytokines concentrations were compared by the Mann-Whitney U test. A p value of $<0.05$ was considered significant.

\section{Results}

\section{Survival of mice after pulmonary infection with L. pneumophila}

Fig. 1 shows the survival kinetics of IFN- $\gamma^{-/-}$mice and control mice after pulmonary inoculation with $L$. pneumophila. At 6 days after challenge, the survival rate of IFN- $\gamma^{-/-}$mice $(8.3 \%)$ was significantly lower than that of the control mice $(92.8 \%, \mathrm{p}<0.01)$. No further change in survival rates occurred after day 6 . The results suggest that there is a relationship between endogenous IFN- $\gamma$ and host resistance to pulmonary infection with L. pneumophila. Within $12 \mathrm{~h}$ of inoculation, L. pneumophila-infected IFN- $\gamma^{-/-}$mice and control mice displayed similar non-specific signs of illness, including lethargy, anorexia and ruffled fur. While these signs resolved within 3-4 days after inoculation in control mice, they worsened in IFN- $\gamma^{-/-}$ mice. 


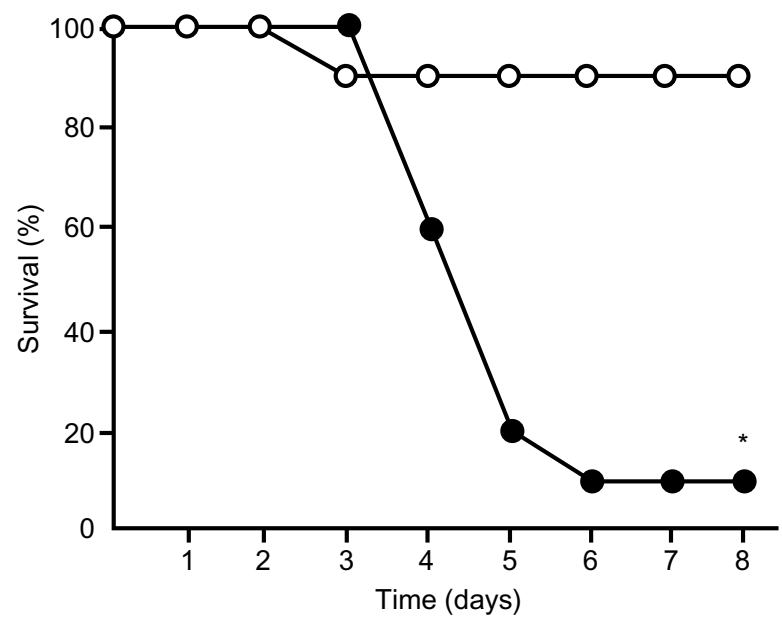

Fig. 1. Survival of mice after pulmonary infection with $L$. pneumophila strain KC. Control mice $(\mathrm{O})(\mathrm{n}=14)$ and IFN$\gamma^{-/-}$mice $(\bullet)(\mathrm{n}=12)$ were inoculated intranasally with $L$. pneumophila at $4 \times 10^{7} \mathrm{cfu} /$ mouse. ${ }^{*} \mathrm{p}<0.01$.

\section{Bacterial clearance}

As shown in Fig. 2, L. pneumophila did not replicate and was cleared from the lungs in control mice. In contrast, L. pneumophila replicated in the lungs of IFN- $\gamma^{-/-}$mice, resulting in a significant increase in bacterial numbers. The number of bacteria recovered from the blood of infected control mice reached a maximum at $48 \mathrm{~h}$ after inoculation and then slowly decreased over the $72 \mathrm{~h}$ after inoculation (Fig. 3). On the other hand, the number of viable L. pneumophila in the blood of infected IFN- $\gamma^{-/-}$mice increased rapidly; the majority of IFN- $\gamma^{-/-}$mice died between days 3 and 6 after inoculation of L. pneumophila.

\section{Inflammatory cells in BAL fluid}

BAL was performed at $6,12,24,48,72$ and $96 \mathrm{~h}$ after pulmonary inoculation of $L$. pneumophila. As shown in Fig. 4, the total number of cells in BAL fluid from

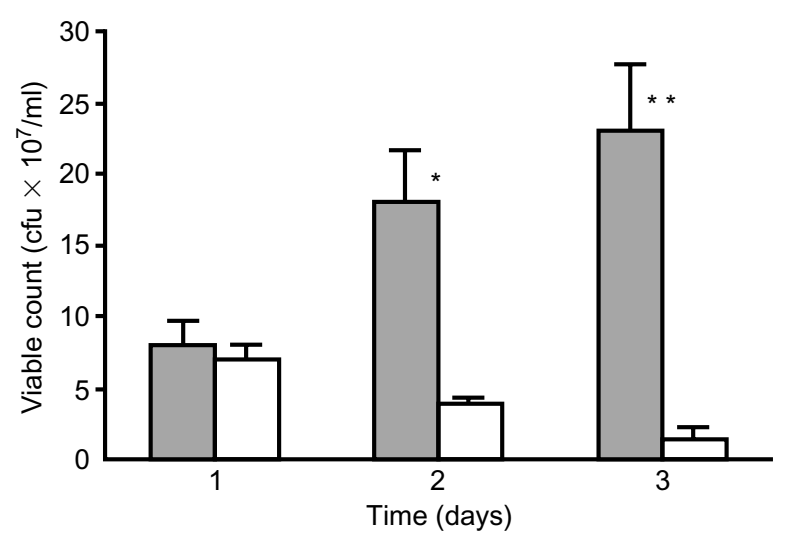

Fig. 2. Viable bacterial counts in lungs of mice after pulmonary infection with $L$. pneumophila. Control ( $\square$ ) and IFN- $\gamma^{-/-}$ $(\square)$ mice were inoculated intranasally with $L$. pneumophila at $4 \times 10^{7} \mathrm{cfu} /$ mouse. Data are mean $(\mathrm{SEM}) \mathrm{cfu} / \mathrm{ml}$ of lung homogenate from seven mice per time point. ${ }^{*} \mathrm{p}<0.05$, $* * \mathrm{p}<0.01$.

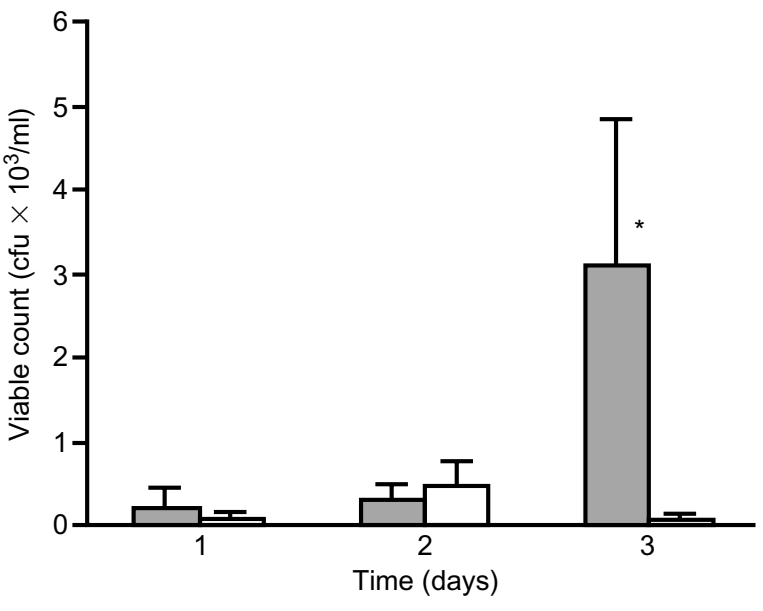

Fig. 3. Viable bacterial counts in blood of mice after pulmonary infection with L. pneumophila. Control $(\square)$ and IFN- $\gamma^{-/-}$

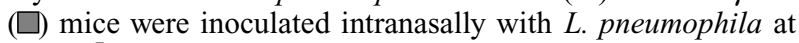
$4 \times 10^{7} \mathrm{cfu} / \mathrm{mouse}$. Data represent the mean $(\mathrm{SEM}) \mathrm{cfu} / \mathrm{ml}$ of blood. ${ }^{*} \mathrm{p}<0.05$.

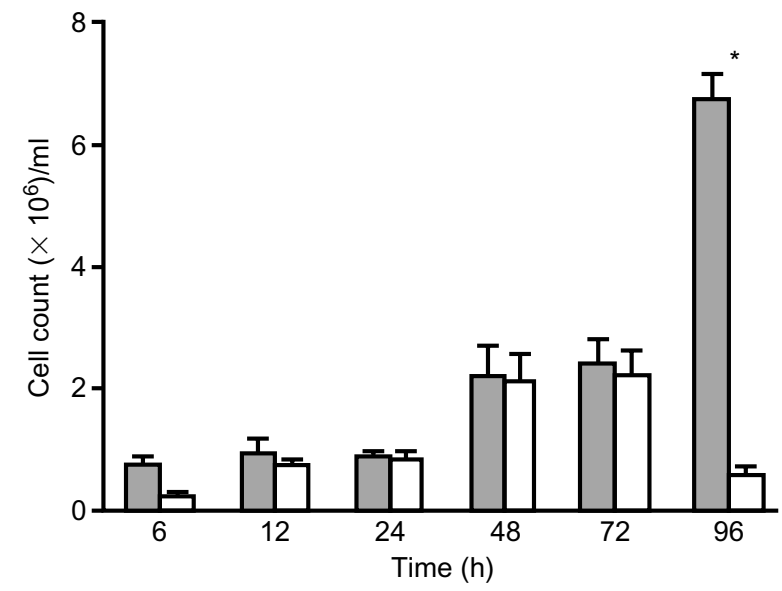

Fig. 4. Total BAL cell counts of control ( $\square$ ) and IFN- $\gamma^{-/-}$( $\square$ ) mice infected with $L$. pneumophila. Data represent the means (SEM) for seven mice per time point. ${ }^{*} \mathrm{p}<0.01$.

IFN- $\gamma^{-/-}$mice was significantly higher than in control mice at $96 \mathrm{~h}$ after inoculation, reflecting the severe pulmonary infection in IFN- $\gamma^{-/-}$mice.

\section{Histopathological findings}

Control mice showed diffuse pulmonary lesions at $12 \mathrm{~h}$ after challenge, which consisted of accumulations of neutrophils and lymphocytes in the interstitium of the lungs (data not shown). Thereafter, control mice showed inflammatory cell infiltration in the alveolar spaces at $24 \mathrm{~h}$ and $48 \mathrm{~h}$, with less inflammation at $72 \mathrm{~h}$ (Fig. 5a) and $96 \mathrm{~h}$. On the other hand, IFN- $\gamma^{-/-}$mice showed pulmonary lesions with a mild infiltration of neutrophils and lymphocytes at $12 \mathrm{~h}$ after challenge and the inflammation increased up to $72 \mathrm{~h}$ after inoculation, i.e., destruction of the alveolar wall and expansion of the interstitial tissue of the lungs with a high level of neutrophil and lymphocyte infiltration (Fig. 5b). The same level of inflammation was also found at $96 \mathrm{~h}$ (data not shown). 

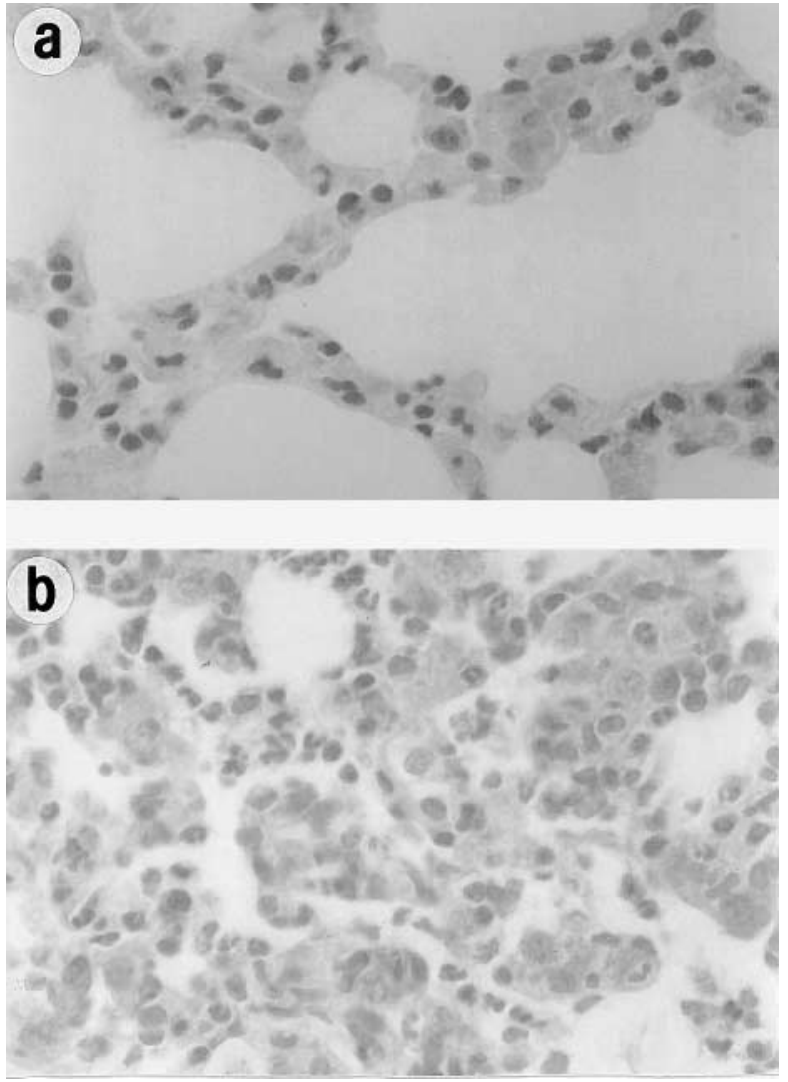

Fig. 5. Lung histopathology in L. pneumophila-infected control mice (a) and similarly infected IFN- $\gamma^{-/-}$mice (b) at $72 \mathrm{~h}$ after infection. Haematoxylin and eosin stain. Magnification, $\times 400$.

\section{Kinetics of inflammatory cytokine production}

As shown in Figs. 6 and 7, in the early stages of infection (up to $12 \mathrm{~h}$ after infection), serum levels of TNF- $\alpha$ and IL- $\beta$ in IFN- $\gamma^{-/-}$mice were significantly lower than in control mice. In contrast, in the late

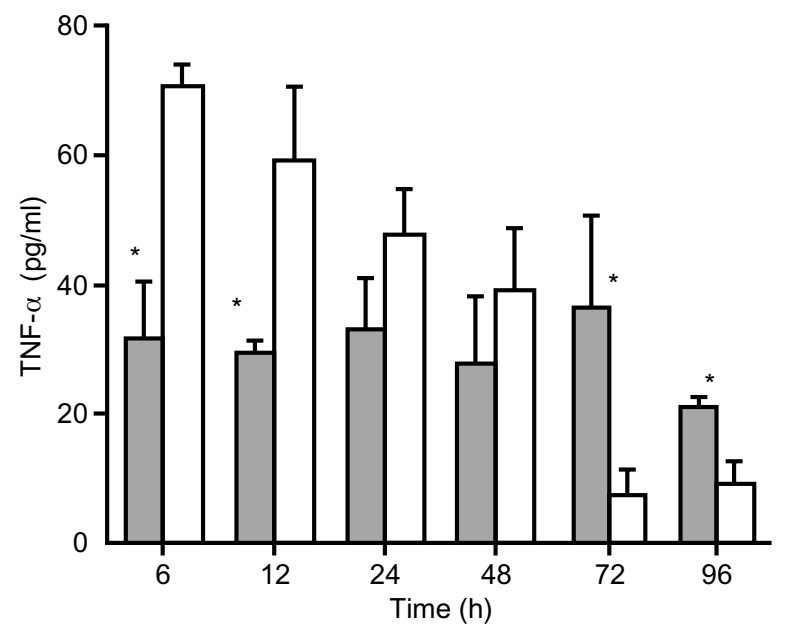

Fig. 6. Kinetics of TNF- $\alpha$ in sera of control ( $\square$ ) and IFN- $\gamma^{-/-}$ $\square$ mice were infected with $L$. pneumophila. TNF- $\propto$ was not detectable at time 0 . Data represent the means (SEM) for seven mice per time point. ${ }^{*} \mathrm{p}<0.05$.

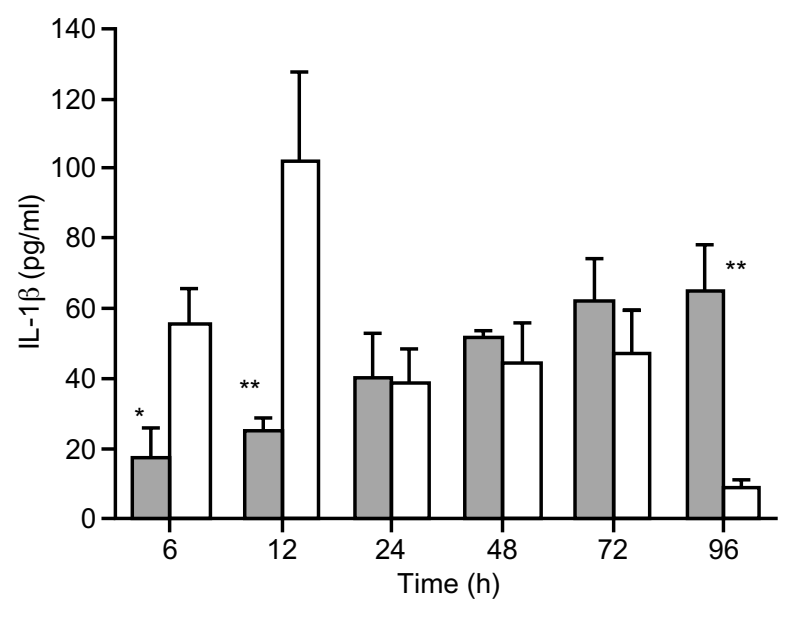

Fig. 7. Kinetics of IL- $1 \beta$ in sera of control ( $\square)$ and IFN- $\gamma^{-/-}$ $(\square)$ mice infected with $L$. pneumophila. IL-1 $\beta$ was not detectable at time 0 . Data represent the means (SEM) for seven mice per time point. ${ }^{*} \mathrm{p}<0.05,{ }^{* *} \mathrm{p}<0.01$.

stages of infection (from $72 \mathrm{~h}$ after infection), the concentrations of these cytokines in the sera of IFN$\gamma^{-/-}$mice were significantly higher than those of control mice.

\section{Discussion}

Previous studies have demonstrated that early nonspecific host immune responses, mediated in large part by cytokines, including IFN- $\gamma$, play a key role in host defence against $L$. pneumophila infections [6,8-11]. Heath et al. [6] studied the role of IFN- $\gamma$ in experimental pneumonia induced by L. pneumophila in IFN $-\gamma^{-/-}$mice. Although they demonstrated that $L$. pneumophila caused severe infection in IFN- $\gamma$-deficient mice, they did not report survival data. In the present study, there was a significantly higher mortality rate in IFN- $\gamma^{-/-}$mice than in immunocompetent control mice after pulmonary infection with L. pneumophila.

In the present study, examination of bacterial clearance showed a continuous increase in the number of viable L. pneumophila in the lungs of IFN- $\gamma^{-/-}$mice, indicating that the lack of IFN- $\gamma$ rendered these mice unable to eliminate the bacteria from the lungs. Because significant difference in the number of inflammatory cells in BAL fluid could be demonstrated between the two groups of mice in the early stage of infection, recruitment of inflammatory cells into the lungs might not significantly affect the clearance of bacteria in this model of infection. In this regard, Heath et al. [6] indicated that IFN- $\gamma$-mediated resolution of $L$. pneumophila pulmonary infection in immunocompetent mice occurs through a NOdependent mechanism. Therefore, NO-dependent bacterial killing might be one of the important mechanisms of clearance of L. pneumophila from the lung tissues. 
TNF is also known as an important cytokine in cellular immunity to L. pneumophila. Treatment of mice with TNF results in significant protection of the animals against death and a significant increase in the rate of clearance of bacteria from the lungs of infected mice [12]. On the other hand, inhibition of endogenous TNF$\alpha$ activity by administration of TNF- $\alpha$-neutralising antibody enhances the growth of L. pneumophila in the lungs of infected mice [13]. L. pneumophila preferentially invades and infects macrophages and monocytes $[14,15]$. Previous in-vitro studies also demonstrated that treatment of macrophage cultures with TNF- $\alpha$ induced resistance of the macrophages to infection by Legionella [16]. These results indicate that not only IFN- $\gamma$ but also TNF- $\alpha$ plays a key role against $L$. pneumophila infection. Although the mechanisms by which TNF- $\alpha$ induced resistance against L. pneumophila infection are still not fully understood, recent studies have shown that TNF- $\alpha$ induction by $L$. pneumophila may be mediated by endogenous NO activity $[17,18]$.

Blanchard et al. [19] reported that the addition of recombinant IFN- $\gamma$ to Legionella-infected murine monocytes resulted in augmented production of TNF in a synergic manner and treatment of murine polymorphonuclear leucocytes with recombinant IFN$\gamma$ and recombinant TNF augmented their bactericidal activity against Legionella in a dose-dependent manner. The present study showed significantly lower serum concentrations of TNF- $\alpha$ in IFN- $\gamma^{-/}$mice than in immunocompetent control mice in the early stage of infection with L. pneumophila. Therefore, it appears that the deficiency of IFN- $\gamma$ influences the production of other inflammatory cytokines, especially TNF- $\alpha$, and consequently influences the overall inflammatory host response to L. pneumophila infection.

Several investigators reported that infection with $L$. pneumophila induces production of IL-1 both in vivo and in vitro $[20,21]$. The results of the present study showed significantly lower serum levels of IL- $1 \beta$ in IFN $-\gamma^{-/-}$mice than in control mice in the early stage of infection. However, McHugh et al. [16] demonstrated that treatment of macrophage cultures in vitro with antibody to IL-1 increased their resistance to infection. IL-1 usually acts synergically with TNF- $\alpha$ to induce resistance. Thus, the results of McHugh et al. [16] seem to be paradoxical. They speculated that their results might be influenced by the existence of an IL-1 receptor antagonist and other forms of inhibitors of IL1. As treatment with recombinant IL-1 had little effect on resistance to Legionella infection [16], the role of IL-1 may be limited, even though it might be beneficial.

Pathological findings revealed that the peak of inflammation in the lungs was seen at $24 \mathrm{~h}$ after inoculation in control mice, whereas $\mathrm{IFN}-\gamma^{-/-}$mice showed the most severe inflammation at $72 \mathrm{~h}$ after inoculation. Therefore, inflammatory cell findings did not reflect what was happening as seen by histology, i.e., the high levels of infiltration of inflammatory cells into the lungs observed by histology at each time point described above were not coincident with the results of the number of cells in BAL fluid at the same time points. It may be that only small numbers of cells from the interstitium were recovered in BAL fluid. Alternatively, there may be a lag in cells moving from the interstitium to the fluid such that the peak of BAL cells at $96 \mathrm{~h}$ resulted from the histological events that took place at $72 \mathrm{~h}$.

Cytokine levels in BAL fluid were measured in this model of $L$. pneumophila infection. However, no significant differences in levels of TNF- $\alpha$ and IL- $\beta$ were found in BAL fluid between the control mice and IFN- $\gamma^{-/-}$mice (data not shown). It may be that analysis of BAL fluid does not always directly reflect the inflammation of the affected site of the lungs at that moment because the main inflamed lesion in this model may be in the interstitium of the lungs.

Newton et al. [20] reported that treating mice with anti-TNF- $\alpha$ antibodies protected them from $L$. pneumophila infection. In their experiment, TNF- $\alpha$ apparently enhanced mortality and their results contradict those reported in the present study. However, in their study, blood and tissue levels of TNF- $\alpha$ were excessively high whereas the levels of TNF- $\alpha$ in the present study were $<10 \%$ of those reported by Newton et al. It appears, therefore, that the production of TNF$\alpha$ following $L$. pneumophila infection can be either protective or detrimental depending upon the infection model.

In the later stages of infection, the levels of TNF- $\alpha$ and IL- $1 \beta$ in the sera of IFN- $\gamma^{-/}$mice were significantly higher than those of control mice. IFN- $\gamma^{-/-}$mice showed apparent impairment of bacterial clearance from their lungs, which resulted in an abrupt increase of bacterial burden not only in the lungs but also in the systemic circulation. Therefore, these high levels of inflammatory cytokines might represent severe and systemic infection in IFN $-\gamma^{-/-}$mice.

The results of the present study and those reported by other investigators $[12,13,16,20-22]$ suggest that resistance and inflammatory responses to Legionella infection result from a complex interaction of inflammatory cytokines. Because these inflammatory cytokines can stimulate the host resistance by activating alveolar macrophages and neutrophils, they are necessary for host defence against legionellosis. It appears, therefore, that a fall in inflammatory cytokine production during the early stages of infection caused by deficiency of IFN- $\gamma$ reduces innate host defence to $L$. pneumophila lung infection and results in severe pulmonary and systemic infection. 


\section{References}

1. Murray HW. Interferon-gamma, the activated macrophage, and host defense against microbial challenge. Ann Intern Med 1988; 108: 595-608.

2. Nathan CF, Murray HW, Wiebe ME, Rubin BY. Identification of interferon-gamma as the lymphokine that activates human macrophage oxidative metabolism and antimicrobial activity. $J$ Exp Med 1983; 158: 670-689.

3. Nash TW, Libby DM, Horwitz MA. IFN- $\gamma$-activated human alveolar macrophages inhibit the intracellular multiplication of Legionella pneumophila. J Immunol 1988; 140: 3978-3981.

4. Jensen WA, Rose RM, Burke RHJ, Anton K, Remold HG. Cytokine activation of antibacterial activity in human pulmonary macrophages: comparison of recombinant interferongamma and granulocyte-macrophage colony-stimulating factor. Cell Immunol 1988; 117: 369-377.

5. Bhardwaj N, Nash TW, Horwitz MA. Interferon- $\gamma$-activated human monocytes inhibit the intracellular multiplication of Legionella pneumophila. J Immunol 1986; 137: 2662-2669.

6. Heath L, Chrisp C, Huffnagle G et al. Effector mechanisms responsible for gamma interferon-mediated host resistance to Legionella pneumophila lung infection: the role of endogenous nitric oxide differs in susceptible and resistant murine hosts. Infect Immun 1996; 64: 5151-5160.

7. Tagawa Y, Sekikawa K, Iwakura Y. Suppression of concanavalin A-induced hepatitis in IFN- $\gamma^{-/-}$mice, but not in TNF$\alpha^{-/-}$mice. Role for IFN- $\gamma$ in activating apoptosis of hepatocytes. J Immunol 1997; 159: 1418-1428.

8. Bhardwaj N, Nash TW, Horwitz MA. Interferon-gamma activated human monocytes inhibit the intracellular multiplication of Legionella pneumophila. J Immunol 1986; 137: 2662-2669.

9. Jenson WA, Rose RM, Wasserman AS, Kalb TH, Anton K, Remold JG. In vitro activation of the antibacterial activity of human pulmonary macrophage by recombinant gamma interferon. J Infect Dis 1987; 155: 574-577.

10. Nash TW, Libby DM, Horwitz MA. IFN-gamma-activated human alveolar macrophages inhibit the intracellular multiplication of Legionella pneumophila. J Immunol 1988; 140: 3978-3981.

11. Skerrett SJ, Martin TR. Recombinant murine interferon- $\gamma$ reversibly activates rat alveolar macrophages to kill Legionella pneumophila. J Infect Dis 1992; 166: 1354-1361.
12. Blanchard DK, Djeu JY, Klein TW, Friedman H, Stewart WE. Protective effects of tumor necrosis factor in experimental Legionella pneumophila infections of mice via activation of PMN function. J Leukoc Biol 1988; 43: 429-435.

13. Brieland JK, Remick DG, Freeman PT, Hurley MC, Fantone JC, Engleberg NC. In vivo regulation of replicative Legionella pneumophila lung infection by endogenous tumor necrosis factor alpha and nitric oxide. Infect Immun 1995; 63: 3258-3258.

14. Horwitz MA, Silverstein SC. Legionnaires' disease bacterium (Legionella pneumophila) multiplies intracellularly in human monocytes. J Clin Invest 1980; 66: 441-450.

15. Winn WC. Legionnaires' disease: Historical perspective. Clin Microbiol Rev 1988; 1: 60-81.

16. McHugh SL, Newton CA, Yamamoto Y, Klein TW, Friedman H. Tumor necrosis factor induces resistance of macrophages to Legionella pneumophila infection. Proc Soc Exp Biol Med 2000; 224: 191-196.

17. Summersgill JT, Powell LA, Buster BL, Miller RD, Ramirez JA. Killing of Legionella pneumophila by nitric oxide in $\gamma$ interferon-activated macrophages. J Leukoc Biol 1992; 52: 625-629.

18. Skerrett SJ, Martin TR. Roles for tumor necrosis factor alpha and nitric oxide in resistance of rat alveolar macrophages to Legionella pneumophila. Infect Immun 1996; 64: 3236-3242.

19. Blanchard DK, Friedman H, Klein TW, Djeu JY. Induction of interferon-gamma and tumor necrosis factor by Legionella pneumophila: augmentation of human neutrophil bactericidal activity. J Leukoc Biol 1989; 45: 538-545.

20. Newton $\mathrm{C}$, McHugh $\mathrm{S}$, Widen $\mathrm{R}$, Nakachi $\mathrm{N}$, Klein $\mathrm{T}$, Friedman H. Induction of interleukin-4 (IL-4) by Legionella pneumophila infection in $\mathrm{BALB} / \mathrm{c}$ mice and regulation of tumor necrosis factor alpha, IL-6, and IL-1b. Infect Immun 2000; 68: 5234-5240.

21. Klein TW, Newton CA, Blanchard DK, Widen R, Friedman H. Induction of interleukin 1 by Legionella pneumophila antigens in mouse macrophage and human mononuclear leukocyte cultures. Zentralbl Bakteriol Mikrobiol Hyg 1987; 265: $462-71$.

22. Arata S, Newton C, Klein TW, Yamamoto Y, Friedman H. Legionella pneumophila induced tumor necrosis factor production in permissive versus nonpermissive macrophages. Proc Soc Exp Biol Med 1993; 203: 26-29. 